\title{
The Internet as a Moral Mediator. The Quest for Democracy
}

\author{
Emanuele Bardone* and Lorenzo Magnani**
}

\author{
* Department of Philosophy and Computational Philosophy Laboratory, University of Pavia, P.zza Botta, 6 - 27100 \\ Pavia, Italy, bardone@unipv.it \\ ** Department of Philosophy and Computational Philosophy Laboratory, University of Pavia, P.zza Botta, $6-27100$ \\ Pavia, Italy \& Department of Philosophy, Sun Yat-sen University, 510275 Guangzhou (Canton), P.R.China, \\ Imagnani@unipv.it
}

\begin{abstract}
Recently the impressive growth of the Web, and the Internet in general, has been considered as a promise that may both challenge and boost our representation of democratic institutions. It is well known that modern democracies are based on the possibility to control and even replace who rules by the force of the best arguments. More generally, the control of the government, and the effectiveness of democracy, is possible, if the citizens can access information. Hence, the promise of the Internet mainly relies on the fact that people may more freely access information, because it seems it cannot be controlled or manipulated by the political power.

In the first part of this outline we will depict a cognitive framework to deal with the relationships between Internet and democracy. We shall show that Internet, as an information technology, can be considered as a cognitive and moral mediator; it can provide stories, texts, images, combined with sounds, so that the information fosters not only a cognitive, but
\end{abstract}

also an emotional and moral understanding. In this sense, the Internet represents a kind of redistribution of the moral effort through managing objects and information to overcome the poverty and the unsatisfactory character of the options available.

In the last part we will illustrate that Internet, as a moral mediator, may enhance democracy in two respects. First, it affords civic engagement and participation; second, it allows people to face different sources of information so that almost everyone can verify and test the information delivered by traditional media.

Keywords: e-democracy, ethics, moral mediator, cognitive mediator, internet

Acknowledgement: Text

\section{Introduction.}

From an intuitive point of view the Internet seems to be an active force that facilitates democratic values. In this paper we will try to provide an answer to the question about whether or not the Internet can enhance democracy We shall start by investigating the relations between humans and computers taking advantage of recent advances brought about by distributed cognition theory. Two important questions have to be considered: first, whether or not technologies (computers included) actively shape the cognitive nature of a certain task. Second, how technologies enhance or extend our capacities to deal with political and moral tasks such as policy making. The first question is about which approach we choose to lead our research; the second regards the reason why technologies, such as the Internet, can be considered, broadly speaking, as a moral (and political) artifact. 


\section{Things that Make us Smart}

In this section we will maintain two important claims about the relations between humans and computers. First, we will claim that technological artifacts are not mere peripheral aids to cognition, but they actively shape it. Second, we shall rely on the concept of task-transforming representation to justify our first claim. More precisely, we will point out that artifacts permit us to transform difficult tasks into simpler ones that can be done by pattern matching (Hutchins, 1995).

In order to shed light on the first issue mentioned above, let us introduce the theory of distributed cognition ${ }^{1}$. According to this theory, human cognition is not something that only happens within the mind. The environment plays a crucial role in cognitive activities, because it provides additional resources, but also because it actually shapes and transforms the task at hand. There are indeed several examples. Consider, for instance, the blind man and his cane (Bateson, 1972). Certainly, the cane is not just an aid, but it is something that completely shapes and even changes the way the blind man can accomplish certain tasks, such as that of walking alone along the street. In this case, the blind man plus his cane can be easily considered as a cognitive system, wherein the boundaries between the mind of the blind man and his cane become trivial from a cognitive perspective. That is to say, we cannot explain how the blind man behaves without also referring to his cane.

In order to better clarify the cognitive role of external resources, we introduce the concept of tasktransforming representation (Hutchins, 1995). As suggested above, artifacts transform difficult tasks into ones that can be done by pattern matching. Let us consider the following example.

As pointed out by Simon (2001), solving a problem means "representing it so as to make the solution transparent". In this passage, Simon seems to argue that a key issue in problem-solving activities is related to the so called representational task. That is, it is related to the ways of representing the problem the agent is facing. The more transparent the agent makes the task, the easier it is to find the proper solution.

Consider, for instance, the following two medical prescriptions (Norman, 1993):

\begin{tabular}{|ll|}
\hline Inderal & -1 tablet 3 times a day \\
Lanoxin & -1 tablet every a.m. \\
Carafate & -1 tablet before meals and at bedtime \\
Zantac & -1 tablet every 12 hours (twice a day) \\
Quinaglute & -1 tablet 4 times a day \\
Coumadin & -1 tablet a day \\
& \\
\hline
\end{tabular}

\begin{tabular}{|l|l|l|l|l|}
\hline & Br & L & D & Bt \\
\hline Lanoxin & & & & \\
\hline Inderal & & & & \\
\hline Quinaglute & & & & \\
\hline Carafate & & & & \\
\hline Zantac & & & & \\
\hline Coumadin & & & & \\
\hline
\end{tabular}

Figure 1: The power of representation

Suppose we should answer to the question "how many pills should I take at lunch time?". We have two different ways of representing the problem. The first consists in a traditional medical prescription that simply tells us what kind of pills we should take, whereas the second consists in a matrix representation. If we compare the two representations we immediately come up with the conclusion that the way the second represents the task is much easier than the first. The reason is that the matrix representation makes the solution more transparent. The medical prescription in the figure on the left is much more complex. The procedure we have to carry out in order to accomplish the task is much more complex: immediately at the first line we need to figure out what " 1 tablet 3 times a day" means. Once we come up with the number of pills we should take, we have to write it down. Then we pass to the second line, and so forth. In contrast, the second representation is much simpler: answering the question means scanning down the lunch column "L" and counting the colored squares. We get the answer at a glance.

${ }^{1}$ On distributed cognition theory see (Norman, 1993, Salamon, 1993, Wilson, 1994, Hutchins, 1995, Clark and Chalmers, 1998, Donald, 2001, Clark, 2003, Wilson, 2004, and Magnani, 2006 ). 
More generally, we can say that we have: 1) a goal (G) to reach; 2) an initial state (IS) that is the starting point. Then we have two different representations of the task RT1 and RT2. The representation of the problem can be viewed as the set (S) of mental operations, but also of actions, manipulations, inferences that we are prompted to obtain our goal. Within this framework, we may argue that the matrix representation is simpler because the procedure it prompts us to carry out is much less complex than the first one. As already pointed out, we must just scan the column and then count. We can represent this process with the diagram of Figure 2 :

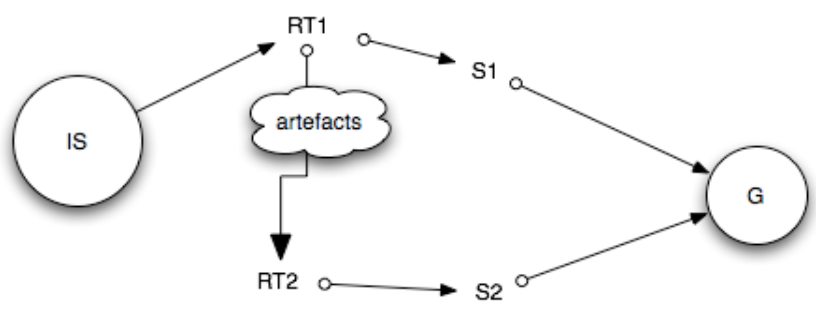

Figure 2: A problem-solving schema

According to our view, we may draw some theoretical implications. First, a problem-solving activity is always a mediated process. That is to say, cognitive tasks are always mediated by a representation ${ }^{2}$. Second, the representation of a task is not only a mental structure. But it can be also viewed as a step by step procedure that emerges from the interaction between humans and the environment. Thus, a representation is also something that happens outside the human mind; in this sense, we may say that a representation is something that is occurring both internally and externally ${ }^{3}$. Third, artifacts, tools, computers, for example, can shape, and even change the representation of a problem so as to make the solution more transparent, as suggested by Simon.

\section{Things that Make us Moral. The Concept of Moral Mediators}

In the previous section we have pointed out that external resources can be considered cognitive mediators that transform the representational task we deal with aimed at making the solution clearer. That is, there are some artifacts that better fit us, because they provide additional resources and make the procedure we have to follow more suitable to humans (Norman, 1993). Something similar can be hypothesized in the case of morality. The question we shall address in the following is related to the role played by external resources in moral reasoning, and in morality in general.

By the term morality we simply refer to all those situations in which humans have to manage problems related, for instance, to making decisions or policies that may have a moral concern and impact on our lives. Morality is also intertwined with the problem of coming up with new ideas that can solve old problems and even create new moral concerns towards new moral entities, such as animals and things.

Why may external resources help us to make better moral decisions? How may external resources contribute to make new and valuable moral discoveries? How can tools, artifacts, such as the Internet, make us better citizens? How can we articulate the moral and political dimension of Human Computer Interaction? And finally, how do things make us moral?

All these questions might sound a bit provocative. Morality and ethics have always been concerned with principles, theories, codes of behavior. Reflection is the main way to be moral and aware of what counts. There are books on morality, but not moral books. The possible "moral agency" of external resources, such as computers, but also paintings, statues, tools, has always been disregarded. Certainly, there are

\footnotetext{
${ }^{2}$ It is worth noting that this conclusion is consistent with the one proposed by Peirce (1972), who argued that we have no power of thinking without signs. For a semiotic account of cognitive processes, see (Magnani, 2006).

${ }^{3}$ On the role of external representations, see also (Zhang, 1997, Wilson, 2004 and Gatti and Magnani, 2005).
} 
several "things" that have acquired some moral value. The greatest works of art are sometimes protected even more than humans. However their moral agency is not entirely acknowledged yet.

In order to shed light on this issue let us make a simple example. According to a recent survey the amount of dollars paid by US to go to war in Iraq is currently about 173 billions $^{4}$. This is a huge amount of money, indeed. However, if we look closer, a number does not show a lot of things. That is, it is not always simple to figure out what "173 billions" really means. Therefore, we need to compare large amounts of money to something else, for instance, to our salary, to make sense of it. Costofwar.com has tried to make sense of the enormous amount of dollars spent for the war in Iraq: it provides a very interesting representation. Let us consider Figure 3:
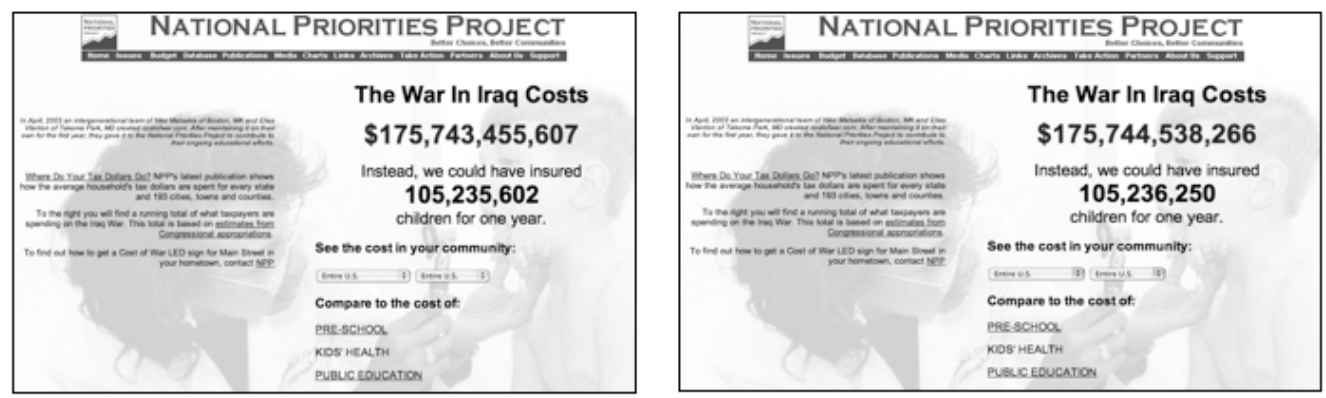

Figure 3. The power of representation: the moral side

In this case the representation provided by the website does not only consist in a twelve digit number, but it is a number that is constantly being updated live by a java script technology. Moreover, it is also compared live as well with what we could have done instead of war. The website furnishes many comparisons, for instance, with the number of children we could have insured, but also with the number of four-year scholarships which could have been provided at public schools, and so on.

This example does not add anything to the fact of the cost of the war in Iraq. However, it represents the same piece of information so that the problem we face, for instance, thinking about going to war or not, is completely changed. First of all, because we have a vivid idea about the amount of money spent. Time provides fundamental clues to make sense of if: we are being updated every second. This representation furnishes also useful comparisons so that it compel us to also think also about the rightness of that war. For instance, wouldn't it be better to pursue different and more life-oriented policies? Was that war so necessary?

We maintain that the website uncovers and unearths certain information that otherwise would have remained invisible or unavailable for making sound judgments. More generally, the point is that without external resources, such as those of the website, we would have made a stronger effort to get an idea about the cost of war. And about that would have been highly time-consuming.

In the previous section, we have pointed out artifacts can be very powerful task-transforming representations. And we have said that the same can be said about morality. Here again we have a problem-solving activity to accomplish, a problem that can have a moral and political concern. Now, we contend that the website can be considered a moral mediator, because it mediates the task changing the representation we have of it, and making the solution more transparent.

Let us introduce the concept of moral mediators. This concept is introduced by Magnani (2005b) to refer to all those situations in which various external resources "overcome the poverty and the unsatisfactory character of the moral options immediately represented or found internally". That is, it consists in a redistribution of the moral effort through managing and manipulating objects and external representations. This concept concludes that morality is a distributed phenomenon. More precisely, the concept of moral mediator can be very useful to illustrate three hypotheses we draw on the nature of morality.

\footnotetext{
${ }^{4}$ Source: http://thecostofwar.com
} 
1) morality is something that does not happen only within the human mind;

2) external resources play a crucial role to get and create new valuable moral information;

3) morality can be considered as a system that incorporates not only minds, but also things.

In the case of the first point, the example of the website clearly shows how external resources play a key role in enhancing the moral understanding of a problem. Given our cognitive limitations, we are not able to immediately detect the moral significance of certain activities or actions. For instance, very often people lean on diagrams or schema just to visualize the consequences of a given decision. Sometimes also empathy requires external aids to be prompted. An image or a picture can help to prompt a kind of moral sentiment that otherwise would remain blind. Therefore, how can we explain moral behaviors and concerns without referring also to the role played by moral mediators?

Consider the example of the ethics of care. In this case, morality is mainly embodied; the ethical response does not rely on abstract rules or principles, but on an implicit and tacit dimension that incorporates feelings, manipulations, emotions, and so on. According to our view, these are all extratheoretical moral behaviors that rely only on external and embodied representations.

The last consideration introduces the second point: external resources, as moral mediators, can help us create new moral values and entities. There are several examples that fairly illustrate this point. Let us consider the example of the "endangered species": when we think of animals in this way, as subjects requiring protection for their own existence, we can also use them to depict new moral features of human beings previously unseen. Also humans can consider themselves as endangered species. In this case endangered species become a mediator that unearths a new moral perspective expanding the notion of moral worth and dignity. ${ }^{6}$ Here again, external objects are employed, as moral resources, to invent and create new moral concerns that otherwise would not be considered.

The third point concerns morality as a distributed system that incorporates not only minds, but also things. It is usually claimed that the moral dimension refers primarily to human beings. This claim is supported by arguing that only humans have intentions: they can only choose consciously, they can only have free will, beliefs, and so forth. In contrast, computers, tools, and external objects in general, lack all those features (free will, consciousness, etc.). Hence, they have no moral agency; they cannot be part of a moral system of any kind. However, the concept of moral mediator may provide a different perspective on the morality of things. As shown above, there are several examples in which artefacts play a crucial role in enhancing our capacities to see moral values. External objects can change the representation of the task we face uncovering additional and valuable information. Our moral performances would drop, if we could not lean on external supports.

In the following section, we will try to apply this general approach to the Internet in order to provide a sound answer about whether or not it can enhance democracy.

\footnotetext{
${ }^{5}$ For further details about this issue, cf. (Nagle, 1998 and Kirkman, 2002).

${ }^{6}$ More details in (Magnani 2005b: chapters one and six).
} 


\section{The Internet as a Moral Mediator. The Quest for Enhancing Democracy}

In this applied section we deal with the problem of the possible impact of Internet on democracy. The question is: why may the Internet challenge and help democracy? What kind of activities may Internet mediate to foster our crippled democracies?

Generally speaking, we maintain that Internet, as a moral mediator, may enhance democracy in two respects. First, Internet allows people to face different sources of information so that almost everyone can verify and test the information delivered by traditional media; second, it affords civic engagement and participation. More precisely, the Internet can be considered as a community builder.

\subsection{Information as democratic resources.}

What people think, what their preferences are, become especially important in democracy. As Karl Popper argued (Popper, 1945), the appeal of democracy rests on the possibility of getting rid of those who rule without bloodshed, but through general elections. Whereas in the other forms of government those who are ruled must make a revolution to dismiss who rules: that is, the force of the best army is the necessary condition to change the government. On the contrary, in democracy information matters, not weapons, because voting is based on ideas and arguments which one can have or get. This leads to two interesting consequences: first, people can influence (and be influenced by) others' views to orient policy makers. Second, public debates and discussions are fundamental to accomplish this task. In this sense, we maintain that a deliberative version fairly represents the appeal of democracy. That is, we claim that discussing matters before making some collective decision constitutes the rationale of democracy; the more people can freely access and participate in public debates and face different opinions, the more democracy serves its purpose.

We provide two arguments to support this conclusion. The first is moral. Discussions allow people to express and debate their preferences. That is, everyone has the chance to have her/his say. Therefore, this makes people more inclined to accept the outcome of a vote, no matter what it would be, because they had the opportunity to discuss it. Moreover, the fact that people can have their say implies everyone has to provide a justification of their ideas. Those claims that cannot be reasonably supported might be discarded.

The second argument is a cognitive one. Debate reveals private information that otherwise would remain folded. Simply having a vote does not contribute to express what one thinks and, most of all, how intense one's preference is (Fearon, 1998). This is crucial to compare different instances and solve inconsistencies. Moreover, discussions are important also for lessening "bounded" rationality. In this case, debate allows people to pool their limited capabilities through discussion (Simon, 1983).

The rationale of democracy rests on its deliberative nature and the fact that none can be excluded, however democracy does not prevent from possible damage or degeneration. As already mentioned, in democracy people's preferences acquire great importance, since people base their vote upon the information and the arguments they face and gather. That is, citizens vote for those who support, or are closest to, their own ideas. However, this is only one face of the coin when considering propaganda. Indeed, propaganda is a necessary condition to keep democracy working. As Bernays put it, "a desire of a specific reform, however widespread, cannot be translated into action until it is made articulate" (Bernays, 1928, p. 57). As a matter of fact, a desire for a certain policy does not come up to the citizens' minds simultaneously (Lippmann, 1921, p. 155): public opinion must be focused and organized. However, citizens' preferences can be easily manipulated and even manufactured. As Chomsky put it, in democracy the government cannot control people by force, but "it can control people's minds" (Chomsky, 2001: p.152). Therefore, the way people can access information, how they build their preferences up, is a key issue to prevent democracy from degeneration.

Now, our claim is that the Internet drastically changes the way people can get and share information. First of all, traditional media (especially those related to the news) can be easily manipulated and 
controlled by the political power who often boosts its agenda by biased, or even bribed, columnists or editors (Furedi, 1997). In contrast, the Internet (and the Net), as an unstructured and ever growing information space, seems to reduce the overall power of government to control citizens (Simon, 2002). The Internet and the Web in particular are searching environments in which people are enabled to search for whatever they want without any kind of filtering. They can access various sources of information and exploit social sources of information such as forums, chat rooms and blogs. In this sense, the Internet dramatically changes the task people face, when they deal with political issues.

\subsection{The Internet as a community builder}

The Internet may enhance democracy in another respect that is related to the problem of political participation and civic engagement. As already mentioned, the rationale of democracy not only concerns voting, but also debating and discussing. However, discussing and debating presuppose that people are truly engaged in all those activities that involve public life. As Putnam (2000) suggested, it is more likely that democracy spreads, when the so called connective tissue of the society is highly developed. The more people are separated from each other, the more the political engagement drastically decreases.

Now, the claim that the Internet allows people to search for whatever they want is well-founded, but it is not the whole deal. As maintained by Meickle (2002), the Internet is not only a medium of consumption, but also of intercreativity. For instance, reading a newspaper is a kind of activity that presupposes a oneway communication flow, so to say. I can read what an editor writes, but she cannot read what I would like to write to her. In this sense, people are primarily information consumers. On the contrary, the new technologies that belong to the so called Internet galaxy (Castells, 2001) make intercreativity possible. By the term intercreativity, we mean something more than simple interactivity. In order to define what intercreativity is, we have to introduce some important distinctions.

For example, several on-line newspapers allow people to select what they want to read or receive in their e-mailbox. Moreover, in many cases, one can post a comment on a given article. However, almost always the options available to the user is limited and already selected by the editor. This is the kind of interactivity exhibited by a jukebox. Second, one can post some comments about a certain story which has been published, but he cannot modify it. These are two examples among others that fairly represent kinds of interactivity.

On the contrary, by the term intercreativity we simply refer to something that is created by a truly twoway communication flow, in which everyone can contribute to producing, choosing, and modifying a given document (an article or the course of an open discussion). For instance, an email exchange with a friend or a forum are examples of this kind.

Now, the fact that the Internet exhibits this kind of intercreativity can play a crucial role in enhancing civic engagement. As mentioned above, the more people are separated from each other, the more the political engagement drastically decreases. Now, the point is that the Internet provides citizens with new possibilities that drastically change the way people can reach each other. That is, citizens cease to be information consumers and become participants, that is a sort of necessary condition to keep democracy working. There are plenty of examples where new political strategies of civic engagement are brought about. No matter where they are, people can share information, make common cause, and jointly advance their mutual political or other agendas (Simon, 2002). Mailing list, newsletters, forums, on-line conference tools, contribute to boost civic engagement. Besides, it is worth noting that also the idea of open publishing promotes those values that are very close to democracy, such as freedom of speech, and so forth.

\section{Conclusion. Some Controversial Issues.}

All along this paper we have tried to provide a cognitive argument, based on the notion of moral mediators, to maintain that the Internet can really enhance democracy. We have argued that artifacts not only actively shape the cognitive task at hand, but they also provide us with fundamental cognitive resources when we have to deal with moral and political issues. First of all, the Internet drastically 
changes the way people can obtain information. We have claimed that in democracy the fact people can freely have access to information is crucial to its rationale. The appeal of democracy is that who rules can be replaced by voting, but citizens' minds can be easily manipulated, if information sources can be controlled by the political power.

Second, the Internet makes people less distant, and contributes to create the connective tissue that is the necessary condition for democracy. As pointed out, citizens are not only information consumers, but also participants, which is the core of democratic societies.

Unfortunately, some issues must still be debated. We find two main pragmatic obstacles for enhancing democracy: the so called digital divide and the information overloading. They do not constitute two arguments against the thesis we have tried to developed along this paper, rather, they tell us how far we are from the exploitation of all the potentialities that the Internet brings to us.

The digital divide is certainly one of the most well known problems related to Internet development. First, it produces a profound gap between the richest countries and the rest of the world. Many attempts are currently performed to develop new solutions. For example, Nicholas Negroponte, the MIT Media Lab chair, has recently lunched a new research initiative to develop a $\$ 100$ laptop $^{7}$. Second, obstacles are not only economical: for instance, aged people are less and less engaged in using new technologies, since they are not sufficiently trained to get a computer working.

The second group of problems is related to what we have called information overloading. In short, the Net, and the Internet in general, consists in such a huge amount of information that we cannot find previous examples. However, its richness is bounded by human limits to cope with large amounts of information. This is due to the fact that the Net is not a simple information space, namely, an environment which contains information, but it is also a searching environment. That is, its wealth is not only given by the amount of information it contains, but also the way it could be actually accessed to. Developing search engines that help people to find the piece of information they want is a crucial point also for democracy, as we have argued in the previous section.

All this opens a row of problems related with retrieval systems. Sunstein (2001) has recently connected the problem of personalization with democracy and the idea of public forum. Even if almost everyone would have only the information he wants to know about (as pointed in the last section), this could encourage people to narrow their horizons (Sunstein, 2001: p. 26). For example, consider a person that is interested in football, fishing and technology. He would not receive any news related to other topics such as education, business or health.

This has important consequences that are also political. From a political point of view, the fact that people can choose exactly the news they are interested in challenges the idea of a public forum. According to Sunstein, democracy is based upon the idea of being exposed to diversity. Moreover, people often refuse to seek out certain options in the first instance. But in the second instance they may change their opinion. Generally speaking, being suggested by others and being exposed to different opinions and interests provides very important cognitive aids. More precisely, it serves two cognitive goals: first, to filter the unmanageable amount of information provided by the net, second, it refines people's own interests.

On the contrary, filtering and personalization leads to isolation: people could become less inclined to being exposed to different opinions or different interests and thus diminish the possibility to understand one another. The considerations above open new questions: how could social problems be addressed by the public opinion within this fragmentation? How should search engines be developed in order to overcome these limitations?

\section{References}

Bateson, G. (1972). Steps to an Ecology of Mind, Chicago: Chicago University Press. Bernays, E. (2005). Propaganda, Brooklin: Ig Publishing (original edition published in 1928).

\footnotetext{
${ }^{7}$ http://laptop.media.mit.edu/
} 
Castells, M. (2001). The Internet Galaxy: Reflections on the Internet, Business, and Society, Oxford: Oxford University Press.

Cavalier, R. (2004). Instantiating Deliberative Democracy. Project PICOLA, European Conference Computing and Philosophy (ECAP2004_ITALY), Abstract, Pavia, June 2-5, 2004, Italy.

Chomsky, N. (2002). Understanding Power, New York: New Press.

Clark A., \& D. J. Chalmers (1998). The Extended Mind, in Analysis 58: 10-23.

Clark, A. (2003). Natural-Born Cyborgs: Minds, Technologies, and the Future of Human Intelligence, Oxford: Oxford University Press.

Davis, S., L. Elin, and G. Reeher (2002). Click On Democracy. The Internet's Power to Change Political Apathy into Civic Action, Cambridge (Mass.): Westview Press.

Fearon, J. D. (1998). Deliberation as discussion, J. Elster (ed), Deliberative Democracy, Cambridge: Cambridge University Press. Furedi, F. (2002). Culture of Fear, London: Continuum.

Gatti, A., and L. Magnani (2005). On the representational role of the environment and on the cognitive nature of manipulations, L. Magnani (ed), Computing, Philosophy and Computing, College Pubblications, forthcoming.

Gibson, J.J. (1979). The Echological Approach to Visual Perception, New Jersey: Erlbaum.

Glassner, B. (1999). The Culture of Fear. Why Americans are Afraid of the Wrong Things, New York: Basic Books.

Hollan, J., Hutchins, E. and Kirsh, D. (2000). Distributed Cognition: Toward a New Foundation for Human-Computer Interaction

Research. Available at: http://hci.ucsd.edu/lab/publications.htm.

Hutchins, E. (1995). Cognition in the Wild, Cambridge (Mass.):The MIT Press.

Kirkman, R. (2002). Through the looking glass: environmentalism and the problem of freedom, in The Journal of Value Inquiry, 36(1):27-41.

Kirsh, D. (1995). The Intelligent Use of Space, in Artificial Intelligence 73: 31-68.

Kirsh, D., P. Maglio (1994). On distinguishing Epistemic from Pragmatic Action, in Cognitive Science 18: 513-549.

Kirsh, D. (2004). Metacognition, Distributed Cognition and Visual Design, Cognition, Education and Comunication Technology, Peter Gardinfors and Petter Johanson (eds.), Lawrence Erlbaum.

Johnson, D.G. (2000). Democratic values and the Internet, D.Langoford, ed, Langford, D., ed., 2000, Internet Ethics, New York, NY: St. Martin Press.

Lippmann, W. (1997). Public Opinion, London: Free Press.

Magnani, L. (2005a). Mimetic minds. Meaning formation through epistemic mediators and external representations, A. Loula, R.

Gudwin, and J. Queiroz (eds.). Artificial Cognition Systems, Idea Group Inc., Hershey, PA forthcoming.

Magnani, L. (2005b). Knowledge as a Duty. Distributed Morality in a Technological World, forthcoming.

Magnani, L. (2006), Semiotic brains and artificial minds. How brains make up material cognitive systems, R. Gudwin and J. Queiroz, eds., Semiotics and Intelligent Systems Development, Idea Group Inc., Hershey, PA, forthcoming.

Magnani, L., E. Bardone, and M. Bocchiola, (2006). Moral Mediators in $\mathrm{HCl}$, Encyclopaedia of $\mathrm{HCl}$, edited by C. Ghaoui, Information Science Publishing, USA.

Meikle, G. (2002). Future Active. Media Activism and the Internet, London: Routledge.

Nagle, J.C. (1998). Endangered species wannabees, in Seton Hall Law Review, 29:235-255.

Norman, D.(1993). Things that Make us Smart, New York: Addison Wesley.

Peirce, C.S. (1972). Questions Concerning Certain Faculties Claimed for Man, in Id., The Essential Writing, edited by E.C.Moore, New York: Harper \& Row.

Perry, M. (2003). Distributed Cognition, J. Carroll (ed), HCl, Models, Theories, and Frameworks, London: Morgan Kaufman.

Popper, K. R. (1945). Open Society and its Enemies, London: Routledge.

Putnam, R. (2000). Bowling Alone, New York: Simon \& Schuster.

Rheingold, H. (2002). The Virtual Community: Homesteading on the Electronic Frontier, Cambridge (Mass.): The MIT Press.

Saco, D., (2002), Cybering Democracy, Minneapolis: University of Minneapolis Press.

Salamon, G. (ed) (1993). Distributed Cognitions, Cambridge: Cambridge University Press.

Simon, H.A. (2001, Third Edition). The Sciences of the Artificial, Cambridge (Mass.): The MIT Press.

Simon, L.D. (2002). Democracy and the Net: a Virtuous Circle?, L.D. Simon (ed), Democracy and the Internet. Allies or Adversaries?, Washington (D.C.): Woodrow.

Stokes, S.C. (1998). Pathologies of deliberation, in J. Elster (ed), Deliberative Democracy, Cambridge: Cambridge University Press. Susi, T. and Ziemke, T. (2001). Social Cognition, Artefacts, and Stigmergy, in Journal of Cognitive Systems Research, 2, $273-290$. Sunstein, C. (2001). Republic.com, New York: Princeton University Press.

Wilson, R. (1994). Wide computationalism, in Mind, 103(411), 351-372.

Wilson, R. (2004). Boundaries of the Mind, Cambridge: Cambridge University Press.

Zhang, J. (1997). The nature of external representations in problem-solving, in Cognitive Science, 21(2), 179-217. 